\title{
Determinant Analysis of Labor Absorption in the Manufacturing Industry Sector in Sulawesi Island (2010-2019)
}

\author{
Andi Naila Quin Azisah Alisyahbana, ${ }^{1, *}$, Fatmawati ${ }^{2}$, Anas Iswanto Anwar ${ }^{3}$ \\ ${ }^{1}$ Magister of Economics Planning and Development Hasanuddin University \\ ${ }^{2}$ Faculty Economy and Business Universitas Hasanuddin, Makassar, Indonesia \\ ${ }^{3}$ Faculty Economy and Business Universitas Hasanuddin, Makassar, Indonesia \\ *Corresponding author.Email: nailaquinn@gmail.com
}

\begin{abstract}
This research aims to analyze the factors that influence the absorption of labor on the island of Sulawesi, Indonesia. In addition, to contribute or provide input to the employment situation and the performance of economic development in the Sulawesi region in particular and in Indonesia in general. This research was conducted in all provinces on the island of Sulawesi with simultaneous equation model analysis using the Stata application. The period of this research is 2010-2019. This research uses panel information with the variables of Minimum Wage, Number of Businesses, Investments as aspects that affect employment, either directly or indirectly through the GRDP of the Manufacturing Industry Zone. The results of the research found that the variables of the Provincial Minimum Wage, Number of Business Units, Investment and GRDP had a significant positive direct influence on the absorption of labor in the manufacturing industry zone. As well as the investment variable on GRDP has a significant negative direct influence and while for indirect influence Investment on labor through GRDP output has a negative influence. The results of this research are also taken into consideration in determining the most important economic policy regarding the pattern of economic development as a dimension of the nation's progress.
\end{abstract}

Keywords: Labor, manufacturing industry, Sulawesi Island

\section{INTRODUCTION}

The problem of economic development can be viewed as a macroeconomic issue in the long term. In general, growing countries seek to achieve progress in the development and economic planning of a region through productivity in the industrial sector. The industrial sector is expected to be the driving sector and lead (the leading sector) in any economic development to be achieved. Robert Solow's theory comments that economic development will be achieved if there is a development in output. Economic growth is one of the most important indicators in assessing the performance of an economy, especially for analyzing the results of economic development that have been carried out by a country or a region.

The manufacturing industry is considered more productive and can share wide-ranging impacts so that it can improve from 2 aspects of input, increase the workforce, create the largest source of foreign exchange, and contribute the most taxes and customs duties. The classical theory that is still relevant to be used in the industrial competition approach is the theory of "five aspects of power" introduced by Porter. Porter explains that the seriousness of competition in an industrial sector is influenced by 5 aspects, namely: (1) the bargaining power of suppliers, (2) the threat from new players, (3) the bargaining power of buyers, (4) the threat from substitute products, and (5) the seriousness of competition between players in one sector [1] Industrial zones have a role as a development priority that can lead (the leading sector) for other zones [2]. This means by focusing on the industrial sector so that it will spur and carry development in other areas such as agriculture, services and others. 
Sulawesi Island is one of the regions in Indonesia that contributes to national and global economic development, especially in the manufacturing zone. The leading sectors of the Sulawesi region are the food and beverage industry products, the construction sector, and trade which dominate almost every province on the island of Sulawesi. The state of employment in the manufacturing industry has not been able to track the pace of progress as produced by the GRDP of the manufacturing industry. This phenomenon is certainly worrying because the state of employment opportunities provided by these industries cannot use all the quality capabilities of the workforce.

In general, according to Purnamawati \& Khoirudin [3] this problem actually occurs because of modernization in the world of work which has given rise to industries that are more capital intensive, namely using technology such as machines and others. From 2010 to 2019 GRDP growth in the manufacturing sector itself occupied the third largest contributor in several Sulawesi island provinces, especially South Sulawesi Province being the main motor supporting economic growth on Sulawesi Island, followed by North Sulawesi and Central Sulawesi.

In implementing the growth of the manufacturing sector, especially in the large and medium industrial sector, it is influenced by several other important factors as will be analyzed in this study, namely, the minimum wage, the number of business units and investment in the manufacturing industry sector. Therefore, based on the description above, the author is interested in analyzing the effect of the Minimum Wage Level (UMP) in the manufacturing industry sector, then on the number of business units in the manufacturing industry sector, then on the investment value in the manufacturing industry sector and finally related to the GRDP of the manufacturing industry sector on absorption. manpower in the manufacturing industry sector in Sulawesi Island Province by conducting scientific research with the title "Analysis of the Role of the Manufacturing Industry Sector on Labor Absorption in Sulawesi Island (2010-2019)"

\section{LITERATURE REVIEW}

\subsection{Labour Absorption Analysis}

The concept of labor has several definitions, one of which is based on Law No. 25 of 1997, the workforce is each man or woman who is and or wants to carry out work, both inside and outside the work bond to produce goods or services to meet the needs of the community. For Boediono in Furqon and Pudjihardjo [4] labor is one aspect of production that is used in the production process. In the production process, workers get income as remuneration for the work they have done, namely wages. Basically, the workforce can be grouped into 2 parts, namely (1) the labor force and (2) the non-labor force.

The increase in the number of people especially those of working age will create a large workforce [5]It is hoped that this large workforce will be able to spur increased economic activity which in the end will improve the welfare of the citizens. In reality, a large population does not always have a positive impact on welfare.

\subsection{Manufacturing Industry}

For the Central Bureau of Statistics, Manufacturing Industry (2016) [6] is an economic activity that carries out the activity of changing an object mechanically, chemically, or by hand so that it becomes a finished or semi-finished object and or an object of less value into an object of greater value, and its nature closer to the end user. The manufacturing industry can be grouped into 4 groups based on the number of workers, namely:

1. Large Industry (100 workers or more),

2. Medium/Medium Industry (20-99 workers),

3. Small Industry (5-19 workers),

4. Micro Industry (1- 4 workers)

\subsection{GRDP of the Manufacturing Industry Sector}

The indicator that is often used to calculate the economic performance of a country is the Gross Domestic Product (GDP), on the other hand the indicator to see the economic performance of a region in a particular country is used GRDP (Gross Regional Domestic Product) which is one of the important indicators to identify the economic situation in a particular country. territory in a certain period, either above or below the current price or above and below the constant price.

For Utami [7] If the value of GRDP increases so that the total value of output or sales in all economic units in a region also increases. The increase in the value of output or sales that the industry tries to promote will promote the industry to increase the number of its workforce.

\subsection{Provincial Minimum Wage (PMW)}

Wages are one of the most sensitive aspects of the work bond. Workers/laborers view Wages as a source of income to meet the living needs of workers/labourers and their families. Psychologically, wages can also produce satisfaction for workers. Ties with Minimum Wage Levels with Employment Absorption, An increase in the wage level will be accompanied by a decrease in the minimum number of workers which means that it will cause an increase in the number of unemployed. At least, with a decrease in the wage level, it will be accompanied by an increase in the demand for labor, which tends to reduce the number of unemployed. 
Gilarson in Sari [8]comments that wages are remuneration for aspects of human labor creation (in a broad sense, including income, overtime pay, benefits).

\subsection{Number of Business Units}

For Matz in Saputri [9] who reported that the increase in the number of industries would increase the amount of output to be produced so that employment would increase and would reduce unemployment or in other words would increase employment. Universally, the development of business units in an area will increase the number of jobs. This means that the demand for labor is also increasing. The number of business units has a positive influence on the demand for labor, meaning that if the business unit of an industry is added, the demand for labor also increases

\subsection{Investment}

Investment is the amount spent by the company to buy goods used for the production process in the long term Utami [7].The manufacturing sector is the main driver of quality, fast and stable growth for the economy as a whole. The manufacturing sector is associated with a higher contribution to growth when compared to the traditional sectors due to its relative size and interrelationships across all sectors of the economy.

\section{METHOD}

This study uses the variables of Minimum Wage, Number of Businesses, Investments as factors that influence employment, either directly or indirectly through the GRDP of the manufacturing industry sector. This research was conducted in all provinces on the island of Sulawesi by looking at the conditions of labor absorption and the driving factors for the emergence of labor absorption on the island of Sulawesi. The period of this research is 2010-2019.

The type of data used in this study is quantitative data, namely data measured in a numerical scale (numbers). This quantitative data is in the form of panel data, which is a combination of time series and cross-sectional data. This study uses secondary data sources from the Central Statistics Agency Indonesia in the form of data on the Minimum Wage, Number of Businesses, education level and GRDP in all provinces on the island of Sulawesi.The data analysis technique used for this research model is multiple linear regression with Simultaneous Equation Model method using Stata software. The equation model of this research can be seen from the following equation:

$$
\begin{aligned}
& Y_{1 i t}=f\left(X_{1}, X_{2}, X_{3}\right)(1) \\
& Y_{2 i t}=f\left(X_{1}, X_{2}, X_{3}, Y_{1}\right)(2)
\end{aligned}
$$

Description:

X $1=$ Minimum Wage

$\mathrm{X} \_$2 $=$Number of Business Units

$\mathrm{X} \_3=$ Investment

Y $1=$ Economic Growth

Y_2=Labor Absorption

Equation model after reduce form can be seen from following this equation :

$\delta_{0}+\delta_{1} \operatorname{Ln} X_{1}+\delta_{2} \operatorname{Ln} X_{2}+\delta_{3} \operatorname{Ln} X_{3}+\mu_{1,2}(3)$

Description:

$$
\begin{aligned}
& \operatorname{Ln} \beta_{0}+\operatorname{Ln} \alpha_{0} \beta_{4}=\delta_{0}(4) \\
& \beta_{1}+\alpha_{1} \beta_{4}=\delta_{1} \\
& \beta_{2}+\alpha_{2} \beta_{4}=\delta_{2} \\
& \beta_{3}+\alpha_{3} \beta_{4}=\delta_{3}(5)
\end{aligned}
$$

\section{RESULT AND DISCUSSION}

\subsection{Result}

The coefficient of determination for the first equation model is Adjusted R Square of 0.6555, which means that the manufacturing sector output growth in Sulawesi Island of $65.55 \%$ can be explained by the provincial

\begin{tabular}{|c|c|c|c|c|c|}
\hline $\begin{array}{c}\text { Variable } \\
\text { Relations } \\
\end{array}$ & coefficient & SE & Z & Sig & $\begin{array}{c}\text { Descriptio } \\
\mathrm{n}\end{array}$ \\
\hline & & 0.043 & & & \\
\hline$X 1 \rightarrow Y 2$ & -0.129885 & 7556 & -2.38 & 0.018 & Significant \\
\hline $\mathrm{X} 2 \rightarrow \mathrm{Y} 2$ & & 0.130 & & & \\
\hline$\Lambda 2$ & 0.3759037 & 9947 & 2.87 & 0.004 & Significant \\
\hline $\mathrm{X} 3 \rightarrow \mathrm{Y} 2$ & 0.0550254 & $\begin{array}{l}0.025 \\
1367\end{array}$ & 2.19 & 0.930 & $\begin{array}{l}\text { No } \\
\text { Significant }\end{array}$ \\
\hline $\mathrm{Y} 1 \rightarrow \mathrm{Y} 2$ & 0.1807567 & $\begin{array}{l}0.059 \\
1333 \\
\end{array}$ & 3.06 & 0.002 & Significant \\
\hline
\end{tabular}
minimum wage, number of manufacturing business units, and investment, while the remaining $34.45 \%$ is explained by another variable.

\begin{tabular}{|c|c|c|c|c|}
\hline $\begin{array}{l}\text { Variable } \\
\text { Relations }\end{array}$ & coefficient & SE & $\mathrm{Z}$ & Description \\
\hline $\mathrm{X} 1 \rightarrow \mathrm{Y} 1 \rightarrow$ & & & 0.02 & significant \\
\hline Y2 & 0.2327163 & 2.18 & 9 & \\
\hline $\mathrm{X} 2 \rightarrow \mathrm{Y} 1 \rightarrow$ & & & 0.00 & significant \\
\hline Y2 & 0.2826226 & 2.84 & 4 & \\
\hline $\mathrm{X} 3 \rightarrow \mathrm{Y} 1 \rightarrow$ & & & 0,00 & \\
\hline Y2 & 0.39709853 & 3,172 & 6 & significant \\
\hline
\end{tabular}

Table 1. The direct effect of the independent variable on the dependent variable

Table 2. The Indirect effect of the independent variable on the dependent variable 


\subsection{Discussion}

\subsubsection{Dirct Effect of the Provincial Minimum Wage (UMP) on employment in the manufacturing industry sector, through the GRDP of the manufacturing industry sector on Sulawesi Island $\underline{(2010-2019)}$}

In the results of the variable analysis of the influence of the Provincial Minimum Wage (UMP) on the manufacturing industry sector through the GRDP variable in the manufacturing industry sector, it shows a coefficient value of 0.129 with the results of $t$ table -2.38 with a significance of $0.018<0.05$, which means less than 0.05 or (significant) at $=5$ percent) so that it is declared significant. The results of this variable data processing are in accordance with the initial hypothesis which states that the influence of the UMP on the employment of the manufacturing industry sector, through the GRDP of the manufacturing industry sector, has a significant negative effect.

The determination of the minimum wage policy is aimed at increasing the wages of workers who still earn below the minimum wage. If nothing else changed, then the average wage of all workers would also increase. However, the reality is not that simple. Pratomo [8], Pusposari [11] and Chengis, Dube, Lindner and Zipperer [12] show that the minimum wage has a negative effect on employment statistically. This means that every increase in the minimum wage results in a reduction in employment.

4.2.2 Indirect Effect of Provincial Minimum Wage (UMP) on Labor Absorption through GRDP in the Manufacturing Industry Sector on Sulawesi Island (2010-2019)

The results of the indirect test between the variables of the influence of the Provincial Minimum Wage (UMP) on the labor absorption variable in the manufacturing industry sector through the GRDP variable in the manufacturing industry sector have a significant positive effect, which shows a coefficient value of $0.232 \%$ with the results of $t$ table 2.18 with a significance of $0.029<0,05$ which means less than 0.05 or (significant at $=5$ percent) so it is declared significant. The results of this variable data processing are in accordance with the initial hypothesis.

Gross Regional Domestic Product as an intervening variable that mediates the minimum wage on employment because the provincial minimum wage is one of the policies that helps to reduce labor problems the government needs to increase economic growth which is one of the development goals. Economic development is an effort to improve people's living standards, expand the workforce and direct income evenly as measured by the high and low real income per capita.

The results of this study are in line with previous research conducted by Warapsari, Hidayat, and
Boedirochminarni [13].The results of the analysis show that the Minimum Wage variable through GRDP has a positive and significant effect on employment in East Java Province. That means if there is an increase in GRDP as an intervening variable, it will increase the absorption of labor in East Java Province. Minimum Wage Policy will then impact how a company is. With the increase in the value of GRDP, it means that the total value added output or sales in all units in a region also increases.

\subsubsection{Direct Effect of Number of Business Units on employment in the manufacturing industry sector on Sulawesi Island (2010-2019)}

Testing on the variable, namely the number of manufacturing business units, has been shown to have a direct and significant effect on employment. The coefficient value obtained is 0.375 with a t count of 2.87 and a probability of $0.004<0.05$. The results of testing the indirect effect through the GRDP of the manufacturing industry sector obtained a coefficient value of $0.282 \mathrm{t}$ count of 2.84 and a probability of 0.004 $<0.05$. Therefore, overall in this test, it is in accordance with the hypothesis at the beginning.

The findings of this study are in accordance with the results of research from Karib [14] which explains that the variable number of business units has a significant effect on employment in the industrial sector of West Sumatra Province, while the effect is positive, which means that the more the number of business units, the higher the number of business units. the number of employed workers.

\subsubsection{Indirect Effect of Number of Business Units on Manpower Absorption through GRDP in the Manufacturing Industry Sector on Sulawesi Island (2010-2019)}

In the results of testing the indirect effect through the GRDP of the manufacturing industry sector, the coefficient value of $0.282 \mathrm{t}$ is 2.84 and the probability is $0.004<0.05$, which means that the number of manufacturing business units has an indirect and significant effect on employment absorption through GRDP which becomes mediating variable. The results of this analysis prove that it is in accordance with the initial hypothesis.

The results of this analysis prove that it is in accordance with the initial hypothesis. It can be indicated that an increase in the number of companies will increase the amount of output that will be produced so that employment will increase and will reduce unemployment or in other words will increase employment. The results of this test have the same analysis with previous research, namely Marselina [15] simultaneously, investment, business units and labor 
have a significant effect on GRDP production value of the industrial sector in Jambi Province.

Job opportunities are not only related to problems in the economic field, but also problems in the social field. The problem of job opportunities is not only about the availability of employment opportunities for the workforce, but also questions whether the existing job opportunities are sufficient to provide adequate compensation for workers. Basically, the number of available jobs describes the ability of business units to absorb labor, while job opportunities describe the large demand for labor in an economy. In other words, economic growth will determine the absorption of job opportunities.

\subsubsection{Direct Effects of Investment on employment in the manufacturing industry sector on Sulawesi} Island (2010-2019)

In testing the investment variable proved to have a direct positive and but not significant effect on employment with a coefficient value of 0.550 with a tcount result of 2.19 indicating that every $1 \%$ additional investment will add $2.19 \%$ and a probability of $0.930>0$ 0.05 . This result is certainly supported by the initial hypothesis that there is a direct influence between the investment variables on employment, although the significance results found are negative and different from the initial hypothesis. It can be concluded that the absorption of labor can be significantly influenced by the investment variable, in other words, that investment is a factor that can determine the absorption of labor significantly. In the development of the Harrod-Domar theory known as the growth theory, investment not only creates demand, but also increases production capacity. The role of physical capital in the growth model is very important, but production capacity can only increase if other resources (physical capital) are enlarged.

- The results of the study are also supported by an analysis conducted by Saputri [9].Investment has a positive effect on employment in the large and medium manufacturing sector, but it is not significant because the investment value in the city of Surabaya is large, but the nature of investment in the city of Surabaya is solid. capital or capital intensive.

The results of this study have similarities with the results of research by Surani et.al [16] with the title the effect of investment on employment in the industrial sector on the island of Papua in 2007-2018, from the results of this study an analysis that domestic investment and foreign investment, directly affects the workforce absorbed in the manufacturing industry sector of Papua Island.

\subsubsection{Indirect Effect of Investment on employment in the manufacturing industry sector through GRDP on Sulawesi Island (2010-2019)}

The results of testing the indirect effect through GRDP obtained a coefficient value of $0.397 \mathrm{t}$ count of 3.172 and a probability of $0.006<0.05$, which means that with the addition of a mediating variable, namely GRDP, the results of the analysis are significantly positive. Thus the stated hypothesis. It is suspected that investment has a positive and significant effect on employment through the GRDP of the manufacturing industry sector.

The results of the study are in accordance with the theory of economic growth according to Harrod-Domar about the role of investment in economic growth and the results of research proposed by Mariana [17] investment has a positive and significant effect on economic growth. This shows that high investment will increase production results, because in the production process costs are needed to purchase raw materials, equipment and pay employee salaries.

\subsubsection{The Effect of GRDP growth output of the manufacturing industry has a direct and significant positive effect on employment in the manufacturing industry sector on the island of Sulawesi}

The GRDP growth of the manufacturing industry has been shown to have a significant positive direct effect on employment in the manufacturing industry sector on Sulawesi Island, as evidenced by the coefficient value of 0.180 and t-count of 3.06 and $p$-value of $0.002<0.05$. Thus, the fourth hypothesis which states "It is suspected that the GRDP growth output of the manufacturing industry has a direct and significant positive effect on employment in the manufacturing industry sector on the island of Sulawesi" is fully supported.

In another study conducted by Muhtamil [18]the results of the regression of the GRDP variable have an effect on employment in districts/cities in Banten Province. The $\mathrm{t}$ value of the independent variable GRDP is $2.480030>1.680(\mathrm{t}$ table) which means it is significant. Research conducted by Wijaya, Toti, and Pailis (2014) by analyzing the factors that influence labor absorption in Riau Province, for the GRDP variable on employment has a positive effect. In a high and sustainable increase in GRDP is the main condition for achieving sustainable economic development so that it will be at the point of increasing prosperity as well.

\section{CONCLUSION}

Based on the results of the study using the simultaneous equation model analysis, the authors obtained conclusions drawn from research on the determinants of labor absorption in the manufacturing industry sector in six provinces on Sulawesi Island (2010-2019) as follows:

a. The results of this study prove that there are 2 variables that have been selected to be variables that have a direct positive and significant effect 
on employment in the manufacturing industry sector on the island of Sulawesi, these variables are the number of business units and the GRDP of the manufacturing industry sector.

b. The results of this study prove that there is 1 variable that was chosen to be a variable that has a direct negative and significant effect on employment in the manufacturing industry sector on the island of Sulawesi, the variable is the Provincial Minimum Wage (UMP).

c. The results of this study prove that there is 1 variable that was chosen to be a variable that has a direct positive and insignificant effect on labor absorption in the manufacturing industry sector on the island of Sulawesi, the variable is the investment value of the manufacturing industry sector.

d. The results of this study prove that the three variables in this study, namely the Provincial Minimum Wage (UMP), Number of Business Units and Investment have a positive and significant indirect effect on employment through the intervening variable GRDP in the manufacturing industry sector on Sulawesi Island.

\section{AUTHORS' CONTRIBUTIONS}

AN wrote the manuscript, provided data, conducted all statistical analyses with software Stata and wrote the conclusion, FW and AI wrote method and proofread the manuscript, and give literature review references, and All authors reviewed the final manuscript.

\section{ACKNOWLEDGMENTS}

The highest appreciation to the Faculty of Economics and Bussines at Universitas Hasanuddin, especially the master's program of development economics and planning in providing the opportunity to carry out this research for the support and also contribution to this review article so it can be accepted in The International Conference on Social, Economics, Business, and Education (ICSEBE 2021)

\section{REFERENCES}

[1] Silalahi, S. A. F. (2014). The Condition of the Indonesian Manufacturing Industry in Facing Globalization. Journal of Economics \& Public Policy, 5(1), 1-13.

[2] Arsyad, Lincoln. 2010. Development Economics, Edition 5.UPP STIM YKPN Yogyakarta. Yogyakarta.

[3] Purnamawati, D. L., \& Khoirudin, R. (2019). Absorption of Manpower in the Manufacturing
Sector in Central Java 2011-2015. Journal of REP (Research on Development Economics), 4(1), 41 52.

[4] Furqon, A. M., \& Pudjihardjo, M. (2013). Analysis of the Effect of GRDP, Minimum Wage, Number of Business Units and Investments on Labor Absorption in the Manufacturing Industry Sector in Gresik Regency in 1998-2012. FEB Student Scientific Journal, 2(2).

[5] Anggoro, M. H. (2015). The effect of economic growth and labor force growth on the unemployment rate in the city of Surabaya. Journal of Economic Education (JUPE), 3(3)

[6] Central Bureau of Statistics. 2016. Indicators of Large and Medium Industries of South Sulawesi Province. Central Bureau of Statistics of South Sulawesi Province. Makassar.

[7] Utami B. (2020). Analysis of Labor Absorption in the Manufacturing Industry Sector (Large and Medium) East Java Province. Journal of Economics Development Issues, 3(01), 38-49..

[8] Sari, R. (2015). The Effect of Investment and District Minimum Wage on Labor Absorption in the Manufacturing Sector in Jember Regency 2001-2013.

[9] Saputri, M. D. (2018). Analysis of the Effect of Number of Business Units, Investment and Minimum Wage on Labor Absorption in the Large and Medium Manufacturing Sector in Surabaya City in 2005-2014. JEB17: Journal of Economics and Business, 3(01).

[10] Pratomo, Devanto. 2010. "The Effects of Changes In Minimum Wage on Employment In The Covered and Uncovered Sectors In Indonesia".Journal of Indonesian Economy and Business. Volume 25, Number 3.hal.261-273

[11]Pusposari, 2010, "Analysis of the Effect of Minimum Wage on Employment Opportunities in the Industrial Sector". Journal of Iqtishoduna Volume 6. No.1. ISSN: 1829-524X.

[12] Chengis, Dube, Lindner and Zipperer.2019. The Effect Of Minimum Wage ForLow Wage Worker. The Quartely Journal of Economic,Vol.134, Ed 3, August2019,p.1405-1454. https://doi.org/10.1093/qje/qjz014

[13]Warapsari, E. B., Hidayat, W., \& Boedirochminarni, A. (2020). Analysis of the Effect of Inflation, GRDP, and Minimum Wage on Labor Absorption in East Java. JIE Journal of Economics, 4(2), 194-207. 
[14]Karib, Abdul. 2012. Analysis of the Effect of Production, Investment, and Business Units on Labor Absorption in the Industrial Sector of West Sumatra. Journal of Management and Entrepreneurship, vol. 3 no. 3.

[15] Marcelina, T. R. (2016). The effect of investment, business units and labor on the production value of the industrial sector in Jambi Province. e-Journal of Economic Perspectives and Regional Development, 5(1), 1-12.

[16] Surani, S., Iek, M., Hutajulu, H., \& Hafizrianda, Y. (2021). The Effect Of Investment On Labor Absorption In The Industrial Sector In Papua Province 2007-2018. Journal of Management: Small and Medium Enterprises (SMEs), 14(3), 277-290.

[17] Mariana. 2014. Effects of Investment Growth, Growth in Labor Absorption on Economic Growth and Changes in Economic Structure in the Province of Bali. Journal of Economics and Business Udayana University 3.6 (2014):330-344.

[18] Muhtamil. (2017), "The Influence of Industrial Development on Labor Absorption in Banten Province". Journal of Regional Development and Financing Perspectives, Vol 4, No 3, pp.199-206 